\title{
An old reagent becomes a new precatalyst
}

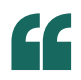

A hetero-
bimetallic
mechanism
for LiAlH
catalysis would
be exciting in
that the matrix
for catalyst
optimization
could be

enormous

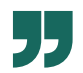

The archetypal reductant in organic chemistry is undeniably $\mathrm{LiAlH}_{4}$, which most often finds use in stoichiometric conversions of polar unsaturated substrates into saturated species. This methodology remains widespread despite its poor atom efficiency - the net addition of $\mathrm{H}_{2}$ to a substrate first requires delivery of $\mathrm{H}^{-}$from $\mathrm{LiAlH}_{4}$ and then $\mathrm{H}^{+}$from a protic solvent. The environmental and economic consequences of this poor efficiency beg the question: can $\mathrm{LiAlH}_{4}$ also serve as a catalyst for the addition of $\mathrm{H}_{2}$ to organic molecules? $\mathrm{LiAlH}_{4}$ catalytically hydrogenates alkynes and 1,3-dienes to their corresponding alkenes, but does so only under forcing conditions. More recent work has shown that $\mathrm{LiAlH}_{4}$ is also a catalyst for the hydroboration of alkenes, ketones and aldehydes. Imines are of intermediate polarity, and a group led by Sjoerd Harder now describes in Angewandte Chemie International Edition a disarmingly mild methodology for their catalytic hydrogenation using $\mathrm{LiAlH}_{4}$.

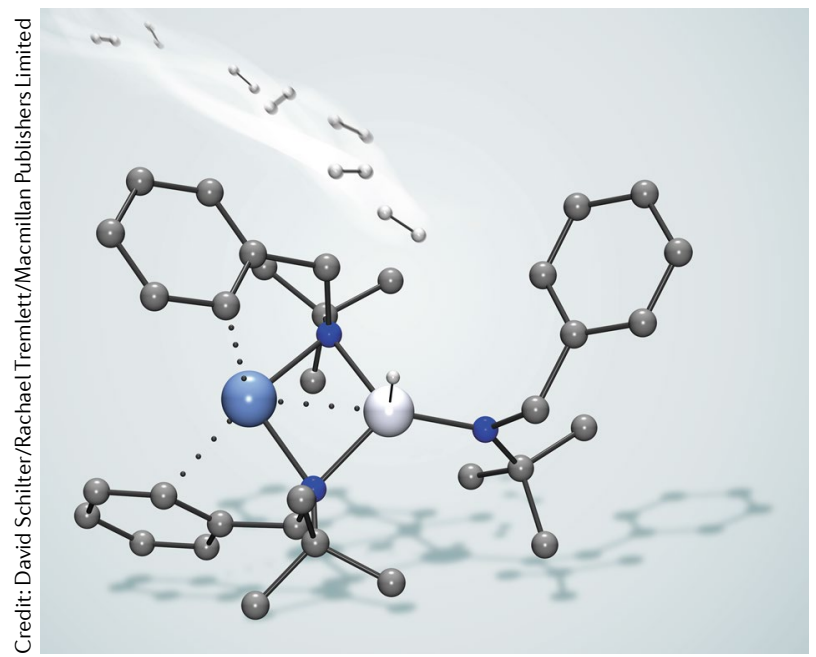

The catalytic reduction of imines is typically the domain of precious metal catalysts, which can oxidatively add $\mathrm{H}_{2}$ and transfer it to a substrate. Such $\mathrm{H}_{2}$ homolysis contrasts the $\mathrm{H}_{2}$ heterolysis that takes place between imines and the Lewis acid $\mathrm{B}\left(\mathrm{C}_{6} \mathrm{~F}_{5}\right)_{3}$, with the former first accepting $\mathrm{H}^{+}$and then $\mathrm{H}^{-}$before becoming an amine. However, the search for another non-transition-metal hydrogenation catalyst continued because $\mathrm{B}\left(\mathrm{C}_{6} \mathrm{~F}_{5}\right)_{3}$ is neither cheap nor compatible with many nucleophiles. Amido hydrides $\mathrm{MH}\left[\mathrm{N}\left(\mathrm{SiMe}_{3}\right)_{2}\right]$ $(\mathrm{M}=\mathrm{Mg}, \mathrm{Ca}, \mathrm{Sr}, \mathrm{Ba})$ are catalysts for imine hydrogenation, so it seemed conceivable that $\mathrm{LiAlH}_{4}$ - long known as a stoichiometric imine reductant - may also be a useful precatalyst. Harder's team found that catalytic amounts of $\mathrm{LiAlH}_{4}$, under merely 1 bar of $\mathrm{H}_{2}$ pressure, convert neat aldimine substrates $\operatorname{Ar}(\mathrm{H}) \mathrm{C}=\mathrm{NR}$ into the amines $\operatorname{Ar}(\mathrm{H})_{2} \mathrm{C}-\mathrm{NHR}$.

The team monitored reaction mixtures and performed independent syntheses of putative intermediates to support their proposed catalytic mechanism. "It is likely that two imine insertions into $\mathrm{LiAlH}_{4}$ afford $\mathrm{Li}(\mu-\mathrm{H})_{2} \mathrm{Al}\left[\mathrm{Ar}(\mathrm{H})_{2} \mathrm{CNR}\right]_{2}$, an active species belonging to a well-studied class of diamido dihydrides," notes Harder. The Lewis acidic Li can bind the $\mathrm{N}$ atom of an imine substrate, with concomitant attack of a bridging hydride ligand on the imine $\mathrm{C}$ atom resulting in a six-membered transition state. The resulting triamido hydride $\mathrm{Li}(\mu-\mathrm{H})$ $\mathrm{Al}\left[\mathrm{Ar}(\mathrm{H})_{2} \mathrm{CNR}\right]_{3}$ is thought to heterolyze $\mathrm{H}_{2}$ through a frustrated Lewis pair mechanism. In this key step, $\mathrm{H}_{2}$ binds both the Lewis acidic Li centre and the lone pair of an amido ligand, after which $\sigma$-bond metathesis liberates the amine product $\mathrm{Ar}(\mathrm{H})_{2} \mathrm{C}-\mathrm{NHR}$ and regenerates the diamido dihydride.

Of the substrates tested, it was $\mathrm{Ph}(\mathrm{H}) \mathrm{C}=\mathrm{N}^{t} \mathrm{Bu}$ that underwent hydrogenation the most smoothly, with Harder and colleagues using just $2.5 \mathrm{~mol}^{2} \mathrm{LiAlH}_{4}$ to achieve $>99 \%$ conversion in $2 \mathrm{~h}$ at $85^{\circ} \mathrm{C}$. Replacing Ph with electronrich or electron-deficient aryls (or a bulky electron-releasing ${ }^{t} \mathrm{Bu}$ group) resulted in lower yields. Similarly, the aliphatic ${ }^{t} \mathrm{Bu} \mathrm{N}$-substituent proved crucial, and its replacement with $\mathrm{Ph}$ caused the reaction to be much slower because the amido ligands in the triamido hydride $\mathrm{Li}(\mu-\mathrm{H}) \mathrm{Al}\left[\mathrm{Ar}(\mathrm{H})_{2} \mathrm{CNPh}\right]_{3}$ are insufficiently basic to deprotonate $\mathrm{H}_{2}$ and effect $\sigma$-bond metathesis. The methodology is presently limited to $\mathrm{N}$-alkyl aldimines, with preliminary testing on alkene substrates being unsuccessful. Likewise, Harder admits that the conditions are unlikely to work for ketones because alkoxo intermediates are unlikely to deprotonate $\mathrm{H}_{2}$. Far from being discouraged, the team is conducting further in silico studies to unravel details of the imine hydrogenation. The cooperativity between one metal and a proximal metal amido might be generalizable. "A heterobimetallic mechanism for $\mathrm{LiAlH}_{4}$ catalysis would be exciting in that the matrix for catalyst optimization could be enormous," says Harder.

David Schilter

ORIGINAL ARTICLE Elsen, $\mathrm{H}$. et al. LiAIH : from stoichiometric reduction to imine hydrogenation catalysis. Angew. Chem. Int. Ed. https://doi.org/ 10.1002/anie.201803804 (2018) 